\title{
ECTOPIC SEBACEOUS GLANDS IN THE ESOPHAGUS: A CASE REPORT WITH REVIEW OF LITERATURE
}

Sapna Patel M.C1, Harish S², Sheela Devi C.S33, Sunila R', Manjunath G.V5

\section{HOW TO CITE THIS ARTICLE:}

Sapna Patel M. C, Harish S, Sheela Devi C. S, Sunila R, Manjunath G. V. "Ectopic sebaceous glands in the esophagus: a case report with review of literature". Journal of Evolution of Medical and Dental Sciences 2013; Vol2, Issue 31, August 5; Page: 5820-5823.

ABSTRACT: Ectopic sebaceous glands occur rarely in the esophagus and have been reported mostly in autopsy studies. A 30-year-old female presented with history of discomfort during swallowing since three months. In upper gastrointestinal endoscopy, two yellowish white lesions were detected in the lower esophagus. Microscopically, they were proved to be sebaceous glands in the esophagus. A case report with review of literature is presented.

KEY WORDS: Esophagus, sebaceous glands, ectopia.

INTRODUCTION: The discovery of sebaceous glands in ectoderm-derived tissues such as oral cavity, parotid glands and external genitalia is a frequent finding. On the contrary, the presence of sebaceous glands in the esophagus, which is an organ of endodermal origin is very rare. There are fewer than thirty cases reported in living individuals. [1] The sebaceous glands in esophagus are interesting because of their doubtful embryonic origin. Several hypothesis have been postulated to explain sebaceous glands in various sites including developmental defects and metaplasia. [2]

CASE REPORTS: A 30-year-old female patient came with the history of discomfort during swallowing for three months. Physical examination and routine laboratory tests were unremarkable. Upper gastro intestinal endoscopy was performed, which revealed two yellowish white nodules of 2$4 \mathrm{~mm}$ diameter in the lower esophagus (Fig 1). The surrounding esophageal mucosa was grossly normal. The clinical diagnosis was esophageal polyp. The nodules were sent for histopathological examination.

Grossly, the specimen consisted of two gray pink tissue bits; each measured 2x2 mms. Microscopically, the non-keratinized stratified squamous epithelial lining showed mild hyperplasia (Fig 2). The submucosa showed several lobules of polygonal cells with small nuclei and abundant clear cytoplasm (Fig 3). No hair follicles were observed. The oil red 0 stain done on cryostat sections revealed negative for fat (neutral lipid). There were no histological features suggestive of reflux or infectious esophagitis. Histological diagnosis of ectopic sebaceous glands in the esophagus was made. The patient was treated symptomatically with antacids and proton pump inhibitors for one month. She became symptom free and remained so at two years of follow up.

DISCUSSION: Sebaceous glands are generally confined to the skin, in close association with hair follicles to form the pilo-sebaceous apparatus, but can be found independently in other organs, where they are known as ectopic or heterotopic sebaceous glands..$^{[3]}$ In adults, the sebaceous glands are unevenly distributed over the body surface, being most numerous on the face, scalp, less numerous over the thorax, abdomen and sparse on the extremities.[1,4] The best known examples of ectopic sebaceous glands are those occurring in the lips and buccal mucosa (referred to as Fordyce's 


\section{CASE REPORT}

spots).[3] It has also been described in various other tissues of ectodermal origin such as eyes, orbits, palms, soles, parotid glands and larynx. Their presence in the esophagus, an organ of endodermal

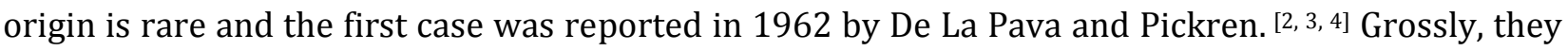
are seen as multiple, minute, yellow white nodules in the mid esophagus. Although no specific clinical symptoms attributable to esophageal sebaceous glands have been identified, some patients may experience symptoms such as heart burn and discomfort during swallowing. [2, 4] These lesions stained slightly with Lugol's iodine solution, and enhanced-magnification endoscopy with narrowband image system revealed that they were encircled by slightly stretched microvessels. When autofluorescence image system was used, the intervening esophageal mucosa was green, whereas the granular lesions were pink or violet. [5]

The histogenesis of sebaceous glands in the esophagus is unclear. Several hypotheses have been postulated to explain the sebaceous glands at various sites. The first hypothesis is embryological misplacement (heterotopia) of sebaceous glands at ectodermal tissue juxtaposed to cutaneous sites. The second hypothesis is metaplasia of submucosal glands. This is favored by the occurrence of this condition in the elderly, and not in children, and because the arrangement of these glands is very similar to the normal anatomic position of esophageal submucous glands. The possible mechanism causing the submucous gland metaplasia of the esophagus is not known at present. $[2,4]$ Ectopic sebaceous glands should be differentiated from other submucosal tumors and proliferative mucosal lesions such as granular cell tumor, leiomyoma, and papilloma. ${ }^{[4,6]}$ There are no reports of any significant complications resulting from this condition. The evidence so far suggests that they are entirely benign in nature and only symptomatic treatment is advised. There are no data that suggest a need for further surveillance endoscopies. [3, 4]

CONCLUSION: Ectopic sebaceous glands in the esophagus are a very rare occurrence. It probably represents a metaplastic change in the esophageal submucosal glands. Being aware of the characteristics will allow the diagnosis of this condition. Further studies are required to elucidate the exact cause and clinicopathological significance of such an unusual epithelial change.

\section{REFERENCES:}

1. Serrano EM, Herranz MJ, Martinez LC, Gonzalez RT, Segura-Cabral JM. Digestive Disease and Pathology. 2010;102(2)

2. Bae JY, Chon CY, Kim H. Sebaceous glands in the esophagus. Journal of Korean Medical Science. 1996; 11(3):271-4.

3. Thalheimer U, Wright JL, Maxwell P, Firth J, Millar A. Sebaceous glands in the esophagus. Endoscopy 2008; 40(2):E57.

4. Bhat RV, Ramaswamy RR, Yelagondanahally LK. Ectopic sebaceous glands in the esophagus: a case report and review of literature. Saudi J Gastroenterol. 2008;14:83-84

5. Kayoko M, Hajime I, Saburo S, Naoyuki Y, Ken O, Yohei M et al. Esophageal sebaceous glands diagnosed after endoscopic mucosal resection. Gastrointestinal Endoscopy. 2009; 69(2):3378.

6. Tak AM, Scott RD, Khan NA. Sebaceous glands in esophagus of a patient with gastroesophageal reflux disease. The internet Journal of Gastroenterology.2007;5:2 


\section{CASE REPORT}

Fig 1: Endoscopy showing two yellowish white nodules in the lower esophagus.

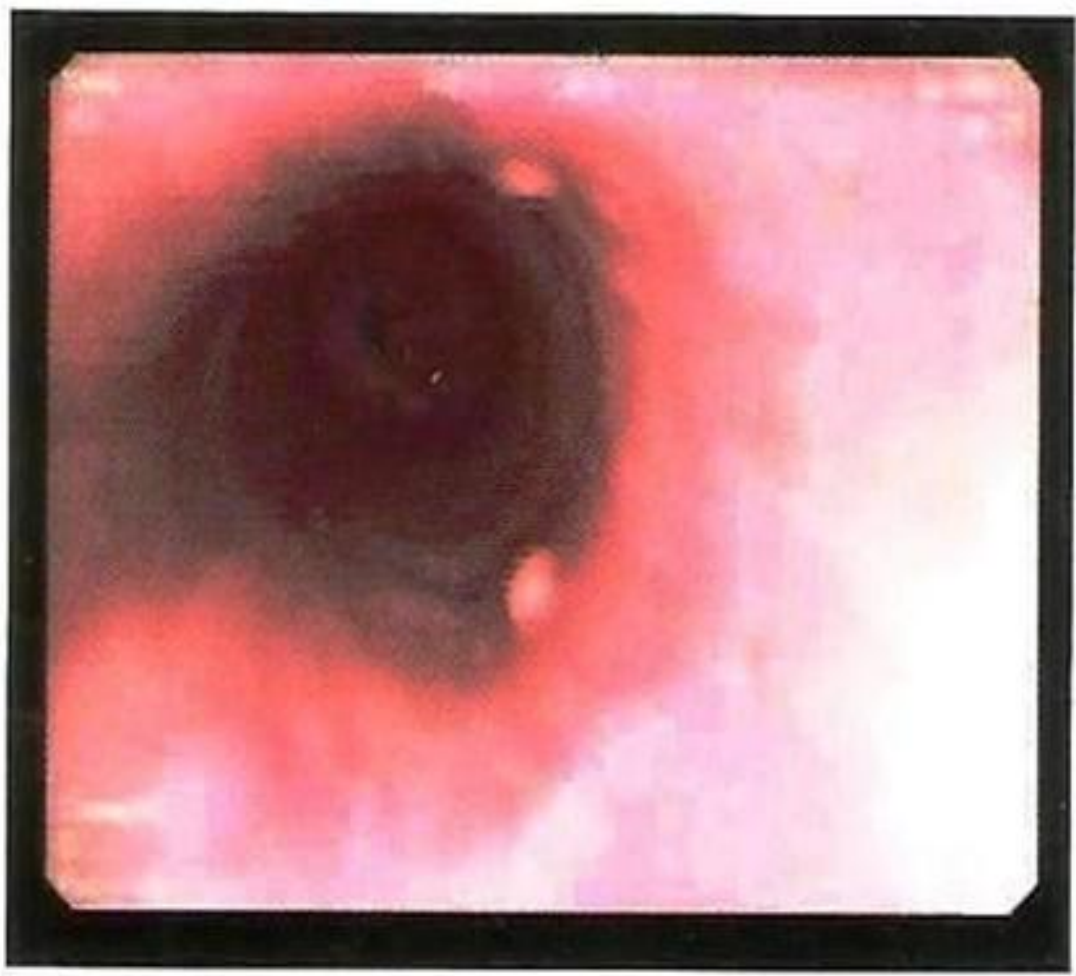

Fig 2: Hyperplasia of esophageal squamous epithelium with sebaceous glands (H \& E, X 100)

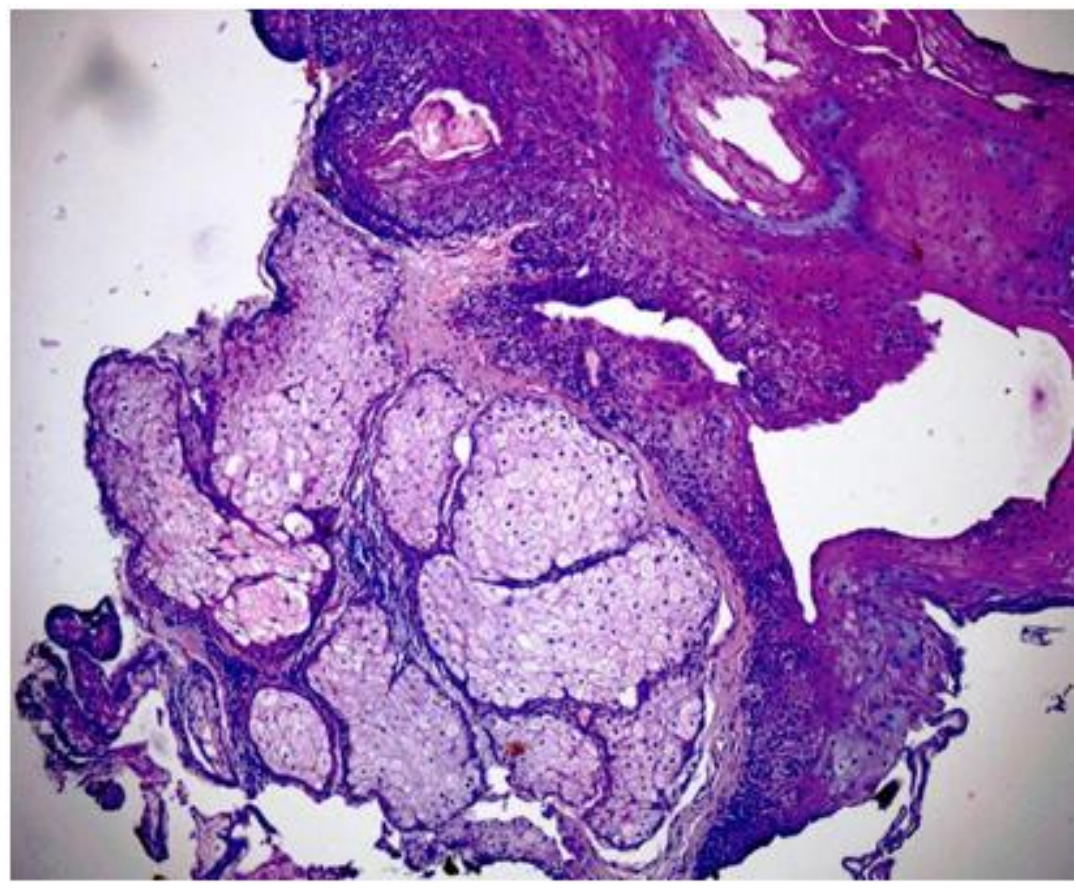




\section{CASE REPORT}

Fig 3: Lobules of sebaceous glands with polygonal cells and abundant clear cytoplasm (H \& E, $\mathrm{X} 200)$

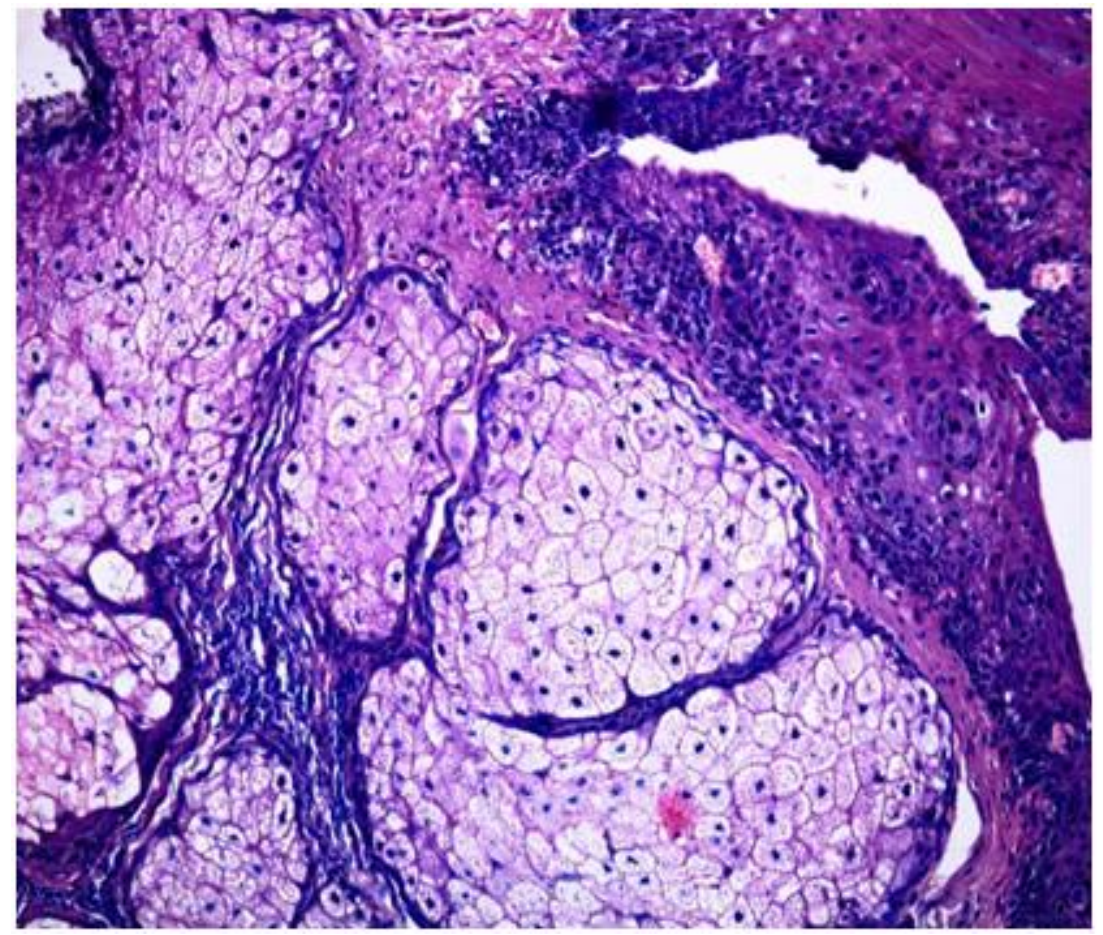

\section{AUTHORS:}

1. Sapna Patel M.C.

2. Harish S.

3. Sheela Devi C.S.

4. Sunila R.

5. Manjunath G.V

\section{PARTICULARS OF CONTRIBUTORS:}

1. Assistant Professor, Dept. of Pathology, JSS Medical College, JSS University, Mysore, Karnataka, India.

2. Associate Professor, Dept. of Surgery, JSS Medical College, JSS University, Mysore, Karnataka, India.

3. Associate Professor, Dept. of Pathology, JSS Medical College, JSS University, Mysore, Karnataka, India.
4. Professor, Dept. of Pathology, JSS Medical College, JSS University, Mysore, Karnataka, India.

5. Professor \& HOD, Dept. of Pathology, Affiliated to JSS Medical College, JSS University, Mysore.

\section{NAME ADRRESS EMAIL ID OF THE CORRESPONDING AUTHOR:}

Dr. Sapna Patel M.C.,

\# 100, Vth Main, Beside Railway Bridge,

Yadavagiri, Mysore,

Karnataka, Pin - 570020.

Email -drsapnaharish@gmail.com

Date of Submission: 20/07/2013.

Date of Peer Review: 22/07/2013.

Date of Acceptance: 23/07/2013.

Date of Publishing: 31/07/2013 